\title{
Treatment of Perforated Diverticulitis with Generalized Peritonitis: Past, Present, and Future
}

\author{
Jefrey Vermeulen · Johan F. Lange
}

Published online: 6 January 2010

(c) The Author(s) 2010. This article is published with open access at Springerlink.com

\begin{abstract}
Background The supposed optimal treatment of perforated diverticulitis with generalized peritonitis has changed several times during the last century, but at present is still unclear. Methods/results The first cases of complicated perforated diverticulitis of the colon were reported in the beginning of the twentieth century. At that time the first therapeutic guidelines were postulated in which an initial nonresectional procedure was provided to be the safest plan of management. After many years in which resection had become standard practice, today, one century later, again (laparoscopic) nonresectional surgery is presented as a safe and promising alternative in treatment of complicated perforated diverticulitis. The question rises what had happened to close the circle?

Conclusions This paper includes a historic summary of changing patterns in surgical strategies in perforated diverticulitis complicated by generalized peritonitis.
\end{abstract}

\section{Introduction}

Perforation with generalized peritonitis is the most common life-threatening emergency requiring surgical intervention in diverticular disease of the colon [1]. Whereas most people with diverticular disease remain asymptomatic, approximately $15 \%$ develop symptoms, and of these $15 \%$ will develop significant complications, such as perforation [2]. In most cases perforation is the first manifestation of the disease [3]. Although the absolute

J. Vermeulen $(\bowtie) \cdot$ J. F. Lange

Department of Colorectal Surgery, Erasmus Medical Center,

Dr Molewaterplein 40, 3015 GD Rotterdam, The Netherlands

e-mail: j.vermeulen.1@erasmusmc.nl prevalence of perforated diverticulitis complicated by generalized peritonitis is low, its importance lies in the significant postoperative mortality, ranging from $4-26 \%$ regardless of selected surgical strategy [1, 4-6].

Until today the optimal treatment for perforated diverticulitis has been a matter of debate. During the last decades, the "gold standard" has changed several times. Primary resection has become the standard practice, but fear of anastomotic leakage often deterred many surgeons from performing primary anastomosis. Therefore, for many surgeons Hartmann's procedure (HP) has remained the favored option for these patients [1]. Nevertheless, improvements in surgical techniques, radiological intervention techniques, anesthesia, advances in intensive care medicine, and progress in the management of peritoneal sepsis have led to an increasing interest in resection with primary anastomosis (PA) with or without diverting stoma or colonic lavage $[5,7,8]$.

Recently, laparoscopic lavage and drainage without resection has been successfully used for patients who have generalized peritonitis caused by perforated diverticulitis (PPD) [9]. Because this nonresectional mini-invasive surgical strategy was associated with a reduction in morbidity and mortality, it might be a promising alternative to the standard open resectional practice [9-11].

This paper includes an overview of the development of different surgical strategies in PPD through the years, and based on this overview we present our personal opinion for the management of this surgical emergency.

\section{Three-staged procedure}

Since the beginning of the previous century, a three-stage operation strategy was common practice for the treatment of 
diverticular disease. The first report of surgical treatment for complicated diverticulitis was by Mayo [12] in 1907. The classic three-stage operation includes an initial diverting colostomy and drainage followed by resection of the involved colon and, finally, a colostomy closure as the third stage. This nonresectional surgery strategy was reaffirmed and advocated by the experiences at the Mayo Clinic, which presented the results in 1924, to be the safest [13].

During the next two decades, indications for emergency surgery evolved toward complicated diverticulitis, such as perforation, obstruction, and fistula formation, only. A preliminary transverse colostomy was advised in all cases in which resection was contemplated, and the period of delay before this resection should be from 3 to 6 months $[14,15]$. The rationale for this strategy was that primary resection is too difficult in the acute stage of the disease, often causing iatrogenic complications and hence mortality. After the fecal stream was diverged by performing a transverse colostomy during the first surgical stage, drainage of the abdomen and pelvic cavity was initiated to diminish sigmoid inflammation. After several months the second stage - resection of the involved bowel—could be performed to treat and prevent relapse of the disease. Smithwick [15] advocated this procedure in favor toward resectional operations. He reported a postoperative mortality after a three-stage procedure of nearby $12 \%$ compared with $17 \%$ if the involved colon segment was resected during initial surgery [15]. Considering that antibiotics were not discovered yet, these results can be regarded as remarkable.

In 1945 Florey [16] was responsible for the development of penicillin for use as a medicine. Since then antibiotics were more frequently used during colonic surgery. Partly, this led toward a shift in the continuing controversy between three- and two-staged operations in favor of primary resection of the involved colon. Although at that time Smithwick [17], amongst others, still recommended the three-stage and initially nonresectional operation [18, 19], more publications advocating primary resection in case of PPD arose [20-22]. Initial improvement after colostomy and drainage, without resection, often was followed by severe deterioration several days later when the involved perforated bowel was left in situ.

Since the 1960s, combinations of antibiotics were used against gram-negative bacteria and anaerobic bacteria. Combination antibacterial therapy had shown better survival in septic patients [23]. Unfortunately, mortality rates in patients with PPD remained high. The basic cause of this high mortality was that the source of infection remained in the peritoneal cavity [21]. Painter and Burkitt [24] documented the increased intraluminal pressures and muscle abnormalities as the cause for diverticula formation in the sigmoid. When left in situ, the perforated segment remains a source of sepsis as bowel contractions continue evacuating infective material. Clinical observations and this new understanding of pathophysiology of diverticulitis led to the conviction that the colonic perforation had to be removed primarily [21, 22]. Nevertheless, controversy persisted because the "evidence" was only based on expert opinion and some (small) noncomparative case series.

\section{Two-staged procedure with primary resection}

Since the 1980s and 1990s, the standard practice of PPD has definitively changed from nonresectional surgery toward primary resection of the involved sigmoid. A twostage operation with the initial operation being resection of the diseased segment with the construction of a colostomy proximally and suture closure of the distal rectal stump became the preferred surgical strategy in these category patients [25]. The second stage was represented by the colostomy closure. Among surgeons this operation has been known since as Hartmann's procedure (HP), although Hartmann [26] himself only performed such a procedure for rectum carcinoma and had advocated that the patient should not undergo restoration of bowel continuity.

This change in strategy was mainly based on the results of two reviews published in 1980 and 1984 by Krukowski and Matheson [27] and Greif et al. [28]. Mortality after primary resection was reported to be lower compared with those procedures in which the perforated segment could not be removed at initial operation $[27,28]$. Unfortunately both reviews were not systematic, containing a wide range of different surgical techniques and covering more than 25 years during which substantial improvements in antibiotic and other perioperative supportive therapies has taken place. Furthermore, it is not known whether the patients of both groups were comparable for a number of essential variables, such as age, ASA classification, and Hinchey and Mannheim Peritonitis Index (MPI) scores.

Between 1993 and 2000, two randomized controlled trials (RCT) assessing primary versus secondary resection were published [29, 30]. These RCTs drew opposite conclusions. Kronborg [29] concluded that three-stage nonresectional surgery (suture and transverse colostomy) in PPD was still superior to primary resection because of a lower postoperative mortality rate. Mortality in Hinchey IV patients was not different in both groups. Unfortunately, the study was preliminary stopped because of low recruitment (an average of four patients each year) and hence underpowered. A total of 62 patients were included and operated by 27 different surgeons during a period of 14 years.

Zeitoun et al. [30] concluded that primary resection was superior to nonresectional surgery because of less 
postoperative peritonitis and fewer reoperations. Nevertheless, postoperative mortality after primary resection was higher compared with nonresectional surgery (24\% vs. $19 \%$ ), but this difference was not significant. Although the evidence was weak, the American Society of Colon and Rectal Surgeons has published practice guidelines in which the three-stage operative approach strategy (nonresectional surgery) was no longer recommended for most patients because of high associated morbidity and mortality [31]. As a result of improvements in radiological intervention techniques, postoperative complications and ongoing abdominal sepsis could be treated percutaneously, which made more radical resections during initial surgery possible [32]. HP had become mandatory for emergency indications in PPD. But skepticism about primary resection remained through the years [33].

\section{Resection with primary anastomosis}

Improvements in surgical and radiological intervention techniques and progress in the management of peritoneal sepsis led to an increasing interest in colonic resection with primary anastomosis (PA) since the 1990s. Although not proven in randomized controlled trials, PA with or without defunctioning loop ileostomy seemed not to be inferior to $\mathrm{HP}$ in terms of severe postoperative complications and mortality [1, 5, 7, 34, 35]. Probably, even the presence of fecal peritonitis was no longer considered an absolute contraindication to immediate bowel reconstruction [36]. However, fear of anastomotic leakage often deters many surgeons from performing a one-stage procedure (e.g., PA in PPD).

Although HP is considered a two-stage procedure, the second stage (reversal of colostomy) will never be performed in a large number of patients [37, 38]. Restoration of bowel continuity after HP is a technically challenging operation and is associated with significant morbidity and mortality [39]. These rates can be as high as $25 \%$ and $14 \%$, respectively, after colostomy reversal in patients who had undergone HP for PPD [1, 5]. Together with the debilitated condition of many of these patients, this is one of the main reasons that HP often results in a permanent colostomy. They face the physical (leakage, parastomal hernia) and psychological (lifestyle alterations) challenges that are associated with having a stoma [40, 41]. The risk of permanent ileostomy is recognizably less than that of HP and with fewer complications [38, 42].

The performance of a diverting loop ileostomy has been reported to decrease the rate of symptomatic anastomotic leakage in patients operated for rectal cancer $[43,44]$. The same is found in case of diverticular peritonitis. However, the quality of the present studies is poor. Besides, a diverting loop ileostomy seems not to diminish postoperative mortality [5]. The use of perioperative colonic lavage appears to lower postoperative complications in case of PA, but the evidence in the present literature is limited $[45,46]$.

Postoperative morbidity and mortality rates of patients after emergency surgery for PPD are still high and mainly caused by the poor general condition of the frequently aged patients and the severity of disease [47-49]. This suggests that further reduction in mortality will require improvement in medical management of pre- and perioperative sepsis and comorbid conditions. Type of surgery seems no longer significantly related with postoperative mortality, although many recent studies favor PA, with or without loop ileostomy, instead of HP in purulent of fecal PPD [6$8,34-36,50]$. These statements were confirmed by a systematic review by Salem and Flum [5] in which mortality rates after $\mathrm{HP}$ and $\mathrm{PA}$ of $19 \%$ and $10 \%$ respectively, were reported.

\section{Nonresectional laparoscopic lavage}

The role of laparoscopic resectional surgery in PPD is limited. In acute complicated diverticulitis without peritonitis, laparoscopic sigmoid resection with PA seemed to be a safe procedure [51]. Outcome after laparoscopic PA in PPD is lacking in the present literature. Laparoscopic HP seems to be a technically feasible procedure with reasonable outcomes for patients in this category [52]. In 1996, Faranda et al. first described a nonresectional laparoscopic procedure that seemed to be a more promising alternative [53]. In patients with peritonitis without gross fecal contamination, laparoscopic peritoneal lavage, inspection of the colon, and the placement of abdominal drains appear to diminish morbidity and improve outcome [10, 11, 53]. In a series of 100 patients with PPD, Myers et al. [9] showed excellent results after laparoscopic lavage and drainage of the peritoneal cavity, with morbidity and mortality rates $<5 \%$.

Laparoscopic damage control surgery seems to decrease the rate of more radical procedures, including HP [11, 54]. In patients who were found to have fecal peritonitis or who fail to improve after lavage, acute resection should still be performed [54]. A comparative study between laparoscopic peritoneal lavage and open PA with diverting loop ileostomy for the management of PPD found no differences in postoperative morbidity and mortality [55]. Laparoscopic peritoneal lavage reduced the length of hospital stay and a stoma could be avoided in most patients.

In a second elective stage definitive surgery can take place, e.g., laparoscopic resection and PA [10, 11], although subsequent elective resection is probably unnecessary 
$[9,56]$. Nevertheless, the number of studies are rather limited and mostly based on small groups of patients. Besides, the rates of additional radiological interventions and conversion to an open procedure are high [54]. Finally, for many hospitals it will not be possible to have a surgical team with expertise in colorectal laparoscopic surgery present all the time. Therefore, laparoscopy is of unclear or limited value in the emergency setting caused by PPD. However, diagnostic laparoscopy may be useful if no diagnosis can be found by conventional diagnostics [57].

Some authors have expressed their concerns with laparoscopic nonresectional treatment of perforated diverticulitis. They state that the decision to perform nonresectional surgery is influenced by the surgical access to the abdomen, i.e., laparoscopy, rather than based on evidence in the literature [58]. Patients should undergo primary resection, whether the surgical access to the abdomen is conventional or laparoscopic, because there is "evidence" in the literature that resectional surgery leads to lower postoperative peritonitis, and mortality rates, compared with nonresectional surgery [58, 59]. Unfortunately, the evidence to which they referred [28-30]—resection favoring nonresectional surgery-is equivocal or to the contrary as stated before. The major criticism of the nonresectional laparoscopically lavage technique is the continued presence of the perforated colon as a septic focus as well as the column of feces remaining in the colon proximally to the perforation as a potential ongoing source of contamination. This also was the main criticism toward the three-stage procedure that was used to treat PPD until the 1970s. Classen et al. had observed that postoperative mortality related to sepsis was lowered after addition of more effective antibiotics to treat gram-negative and anaerobic bacteria since 1970 [19]. Besides, PPD is accompanied by ileus, hence, it is not likely that the fecal column is propelled toward the perforation. A patent communication between the colonic lumen and the peritoneal cavity usually cannot be found during laparoscopy because the site of the original perforation has become sealed by the inflammatory process and omentum and seems efficient to control the source of contamination. If the perforation site is too large to be sealed before peristalsis resumes, resection of the bowel segment is advocated [60].

The suggestion that nonresectional surgery in combination with more advanced antibiotics have never proven to be an inferior strategy could explain the excellent results after laparoscopic lavage in combination with modern management of peritoneal sepsis with improved antibiotics and intensive care medicine. Naturally the latter technique has several advantages over the open three-stage procedure, of which less wound complications (such as infections and hernias), no stomal complications, and avoidance of a second operation are the most important $[9,19]$. Nevertheless, because the evidence is weak, until now primary resection remains the standard treatment for PPD, although the European Association for Endoscopic Surgery Evidence-based Guidelines stated that laparoscopic nonresectional surgery may be considered in selected patients [57].

\section{Nonresectional nonsurgical lavage}

Until the 1990s, all stages of perforated diverticulitis were treated by surgery. The principles of primary treatment of abdominal infections caused by perforation, as outlined by Polk in 1979 [61] have not changed much during the years. These principles include alimentary tract decompression, fluid resuscitation, antibiotics to cover gram-negative aerobes and anaerobes, and so-called "source control." Source control consists of all measurements to eliminate the source of infection, to control ongoing contamination, and to restore premorbid anatomy and its function [61, 62].

The progress of antibiotic development and interventional radiographic techniques has changed the management of perforated diverticulitis. The high specificity of CT scan has allowed this modality to become a surrogate to the perioperative assessment made by the Hinchey classification [63]. Furthermore, CT scan has become an important therapeutic modality. It is now recognized that patients with small, contained perforations, who are not systemically ill, can be treated initially with antibiotics alone or by CT-guided percutaneous drainage [62, 64]. Source control by percutaneous drainage has become the treatment of choice for most abscesses, provided that adequate drainage is possible and no debridement or repair of anatomical structures is necessary [65]. The size of the drain used is very important because complete evacuation of the abscess must be obtained. If the abscess cannot be drained sufficiently, source control will fail. Although mechanical control of the source of infection remains important, several studies have found that abscesses up to $4 \mathrm{~cm}$ seem to respond better to antibiotics alone [62, 64]. Currently, the only patients who require surgery (laparoscopically or open) for source control are those who fail conservative treatment and those who require emergency surgery, mostly patients with PPD [64, 65].

If nonresectional laparoscopic lavage and drainage to treat PPD is found to be a safe and better alternative for resectional surgery in the future, why should this be different from nonresectional nonsurgical, e.g., CT-guided, percutaneous lavage and drainage? The present literature as yet does not report about this (hypothetical or future) treatment strategy. Is it possible that this will be the next step in the ever more conservative management of different stages in diverticular disease? 
To answer this question, it is important to take into account the main principles of abdominal infection treatment when using percutaneous lavage and drainage. Fluid resuscitation and modern antibiotic strategies will not be different from laparoscopically lavage procedures. To gain source control in percutaneous techniques, it is important that large-size catheters will be used for adequate drainage of thick and viscous purulent contents [66]. The main problem is the inability for inspection of the abdominal cavity to localize the site and size of the perforation. In laparoscopic procedures to treat PPD, careful removal of adherent omentum or bowel is tried to locate the site of perforation. If clearly adherent, the adhered omentum or small intestinal loops can be left in place and the abdominal cavity is irrigated with liters of warm saline [9]. At the end of the procedure, one or more drains are inserted. Such a careful adhesiolysis and inspection of the abdominal cavity, to look for or exclude other causes of generalized purulent peritonitis, is not possible using today's radiographic modalities. Furthermore, in case of a large perforation, causing fecal peritonitis, source control by percutaneous lavage and drainage is impossible and hence surgical treatment will be necessary to achieve source control and restore premorbid anatomy and function. It is, therefore, not likely that percutaneous (nonsurgical) nonresectional lavage and drainage will play a prominent role in the treatment of PPD in the near future, because it cannot meet the principles of abdominal infection treatment yet.

\section{Conclusions}

During the last century, mortality rates after emergency surgery for PPD have remained high: nearly $20 \%$. Progress in (antibiotic) sepsis management has led to more radical surgical procedures, but survival did not improve significantly. The reason for this remains unclear. The question arises whether "old-fashioned" (laparoscopic) nonresectional surgery in combination with "modern" sepsis management is the key to success. The last reports are promising.

In our personal opinion, supported by the existing literature about treatment of PPD, resection with PA should be the standard procedure in the emergency surgery for perforated diverticulitis with generalized peritonitis. HP must seriously be considered the surgical procedure of choice for older patients with multiple comorbidities, realizing that restoration of bowel continuity is not an issue. Laparoscopic nonresectional surgery is regarded as a good alternative in case of purulent peritonitis, provided that it is performed by a surgeon who is experienced in laparoscopic surgery. Although currently, percutaneous drainage of abdominal abscesses is the preferred treatment strategy in contained diverticular perforations, it is not likely that nonresectional interventional radiographic techniques will play a prominent role in the initial treatment of PPD in the near future. Clearly, more (prospective randomized) research is warranted to confirm all of these statements.

Open Access This article is distributed under the terms of the Creative Commons Attribution Noncommercial License which permits any noncommercial use, distribution, and reproduction in any medium, provided the original author(s) and source are credited.

\section{References}

1. Vermeulen J, Gosselink MP, Hop WCJ, Lange JF, Coene PPLO, van der Harst E, Weidema WF, Mannaerts GHH (2009) Hospital mortality after emergency surgery for perforated diverticulitis. Ned Tijdschr Geneesk 153:1209-1214

2. Parks TG (1975) Natural history of diverticular disease of the colon. Clin Gastroenterol 4:53-69

3. Hart A, Kennedy J, Stebbings W (2000) How frequently do large bowel diverticular perforate? An incidence and cross-sectional study. Eur J Gastroenterol Hepatol 12:661-666

4. Morris CR, Harvey IM, Stebbings WS, Hart AR (2008) Incidence of perforated diverticulitis and risk factors for death in a UK population. Br J Surg 95:876-881

5. Salem L, Flum DR (2004) Primary anastomosis or Hartmann's procedure for patients with diverticular peritonitis? A systematic review. Dis Colon Rectum 47:1953-1964

6. Constantinides VA, Tekkis PP, Senapati A (2006) Association of Coloproctology of Great Britain Ireland. Prospective multicentre evaluation of adverse outcomes following treatment for complicated diverticular disease. Br J Surg 93:1503-1513

7. Schilling MK, Maurer CA, Kollmar O, Buchler MW (2001) Primary vs. secondary anastomosis after sigmoid colon resection for perforated diverticulitis (Hinchey Stage III and IV): a prospective outcome and cost analysis. Dis Colon Rectum 44:699-703

8. Hoemke M, Treckmann J, Schmitz R, Shah S (1999) Complicated diverticulitis of the sigmoid: a prospective study concerning primary resection with secure primary anastomosis. Dig Surg $16: 420-424$

9. Myers E, Hurley M, O'Sullivan GC, Kavanagh D, Wilson I, Winter DC (2008) Laparoscopic peritoneal lavage for generalized peritonitis due to perforated diverticulitis. Br J Surg 95:97-101

10. Franklin ME Jr, Portillo G, Treviño JM, Gonzalez JJ, Glass JL (2008) Long-term experience with the laparoscopic approach to perforated diverticulitis plus generalized peritonitis. World J Surg 32:1507-1511

11. Bretagnol F, Pautrat K, Mor C, Benchellal Z, Huten N, de Calan L (2008) Emergency laparoscopic management of perforated sigmoid diverticulitis: a promising alternative to more radical procedures. J Am Coll Surg 206:654-657

12. Mayo WJ, Wilson LB, Griffin HZ (1907) Acquired diverticulitis of the large intestine. Surg Gynecol Obstet 5:8-15

13. Judd ES, Pollack LW (1924) Diverticulitis of the colon. Ann Surg $80: 425-438$

14. Lockhart-Mummery JP (1938) Late results of diverticulitis. Lancet 2:1401-1404

15. Smithwick RH (1942) Experiences with the surgical management of diverticulitis of the sigmoid. Ann Surg 115:969-983

16. Florey HW (1945) Use of micro-organisms for therapeutic purposes. Br Med J 2:635-642 
17. Smithwick RH (1960) Surgical treatment of diverticulitis of sigmoid. Am J Surg 99:192-205

18. Miller DW, Wichern WA (1971) Perforated sigmoid diverticulitis. Appraisal of primary versus delayed resection. Am J Surg 121:536-540

19. Classen JN, Bonardi R, O’Mara CS, Finney DC, Sterioff S (1976) Surgical treatment of acute diverticulitis by staged procedures. Ann Surg 184:582-586

20. Smiley DF (1966) Perforated sigmoid diverticulitis with spreading peritonitis. Am J Surg 111:431-435

21. Large JM (1964) Treatment of perforated diverticulitis. Lancet 1:413-414

22. Eng K, Ranson JCH, Localio SA (1977) Resection of the perforated segment. A significant advance in treatment of diverticulitis with free perforation or abscess. Am J Surg 133:67-72

23. Jacobson MA, Young LS (1986) New developments in the treatment of Gram-negative bacteremia. West J Med 144:185-194

24. Painter NS, Burkitt DP (1963) Intrasigmoid pressures in diverticulosis of the colon. Br Med J 2:309

25. Auguste L, Borrero E, Wise L (1985) Surgical management of perforated colonic diverticulitis. Arch Surg 120:450-452

26. Hartmann H (1923) Note sur un procédé nouveau d'extirpation des cancers de la partie terminale due côlon. Bull Mém Soc Chir Paris $1474-1477$

27. Krukowski ZH, Matheson NA (1984) Emergency surgery for diverticular disease complicated by generalized and faecal peritonitis: a review. Br J Surg 71:921-927

28. Greif JM, Fried G, McSherry CK (1980) Surgical treatment of perforated diverticulitis of the sigmoid colon. Dis Colon Rectum 23:483-487

29. Kronborg O (1993) Treatment of perforated sigmoid diverticulitis: a prospective randomized trial. Br J Surg 80:505-507

30. Zeitoun G, Laurent A, Rouffet F, Hay JM, Fingerhut A, Paquet JC, Peillons C, Research TF (2000) Multicentre, randomized clinical trial of primary versus secondary sigmoid resection in generalised peritonitis complicating sigmoid diverticulitis. $\mathrm{Br} \mathbf{J}$ Surg 87:1366-1374

31. Wong WD, Wexner SD, Lowry A, Vernava A III, Burnstein M, Denstman F, Fazio V, Kerner B, Moore R, Oliver G, Peters W, Ross T, Senatore P, Simmang C (2000) Practice parameters for the treatment of sigmoid diverticulitis-supporting documentation. The Standards Task Force. The American Society of Colon and Rectal Surgeons. Dis Colon Rectum 43:290-297

32. Wilson RF (1985) Special problems in the diagnosis and treatment of surgical sepsis. Surg Clin North Am 64:965-989

33. Peoples JB, Vilk D, Maguire JP, Elliott DW (1990) Reassessment of primary resection of the perforated segment for severe colonic diverticulitis. Am J Surg 159:291-293

34. Gooszen AW, Tollenaar RA, Geelkerken RH, Smeets HJ, Bemelman WA, Van Schaardenburgh P et al (2001) Prospective study of primary anastomosis following sigmoid resection for suspected acute complicated diverticular disease. Br J Surg 88:693-697

35. Richter S, Lindemann W, Kollmar O, Pistorius GA, Maurer CA, Schilling MK (2006) One stage sigmoid colon resection for perforated diverticulitis (Hinchey stages III and IV). World J Surg 30:1027-1032

36. Medina VA, Papanicolaou GK, Tadros RR, Fielding LP (1991) Acute perforated diverticulitis: primary resection and anastomosis? Conn Med 55:258-261

37. Maggard MA, Zingmond D, O'Connell JB, Ko CY (2004) What proportion of patients with an ostomy (for diverticulitis) gets reversed? Am Surg 70:928-931

38. Vermeulen J, Coene PP, Van Hout NM, van der Harst E, Gosselink MP, Mannaerts GH, Weidema WF, Lange JF (2009) Restoration of bowel continuity after surgery for acute perforated diverticulitis. Should Hartmann's procedure be considered a onestage procedure? Colorectal Dis 11:619-624

39. Banerjee S, Leather AJM, Rennie JA, Samano N, Gonzalez JG, Papagrigoriadis S (2005) Feasibility and morbidity of reversal of Hartmann's. Colorectal Dis 7:454-459

40. Nugent KP, Daniels P, Stewart B, Patankar R, Johnson CD (1999) Quality of life in stoma patients. Dis Colon Rectum 42(12):1569-1574

41. Gooszen AW, Geelkerken RH, Hermans J, Lagaay MB, Gooszen HG (2000) Quality of life with a temporary stoma: ileostomy vs. colostomy. Dis Colon Rectum 43:650-655

42. Bell C, Asolati M, Hamilton E, Fleming J, Nwariaku F, Sarosi G, Anthony T (2005) A comparison of complications associated with colostomy reversal versus ileostomy reversal. Am J Surg 190:717-720

43. Gastinger I, Marusch F, Steinert R, Wolff S, Koeckerling F, Lippert H (2005) Working Group "Colon/Rectum Carcinoma”. Protective defunctioning stoma in low anterior resection for rectal carcinoma. Br J Surg 92:1137-1142

44. Matthiessen P, Hallböök O, Rutegård J, Simert G, Sjödahl R (2007) Defunctioning stoma reduces symptomatic anastomotic leakage after low anterior resection of the rectum for cancer: a randomized multicenter trial. Ann Surg 246:207-214

45. Kressner U, Antonsson J, Ejerblad S, Gerdin B, Påhlman L (1994) Intraoperative colonic lavage and primary anastomosisan alternative to Hartmann procedure in emergency surgery of the left colon. Eur J Surg 160:287-292

46. Regenet N, Pessaux P, Hennekinne S, Lermite E, Tuech JJ, Brehant O, Arnaud JP (2003) Primary anastomosis after intraoperative colonic lavage vs. Hartmann's procedure in generalized peritonitis complicating diverticular disease of the colon. Int $\mathbf{J}$ Colorectal Dis 18:503-507

47. Makela J, Kiviniemi H, Laitinen S (2005) Prognostic factors of perforated sigmoid diverticulitis in the elderly. Dig Surg 22:100106

48. Pisanu A, Cois A, Uccheddu A (2004) Surgical treatment of perforated diverticular disease: evaluation of factors predicting prognosis in the elderly. Int Surg 89:35-38

49. Oomen JTL, Engel AF, Cuesta MA (2005) Mortality after acute surgery for complications of diverticular disease of the sigmoid colon is almost exclusively due to patient related factors. Colorectal Dis 8:112-119

50. Abbas S (2007) Resection and primary anastomosis in acute complicated diverticulitis, a systematic review of the literature. Int J Colorectal Dis 22:351-357

51. Zdichavsky M, Granderath FA, Blumenstock G, Kramer M, Küper MA, Königsrainer A (2009) Acute laparoscopic intervention for diverticular disease (AIDD): a feasible approach. Langenbecks Arch Surg Surg 19:1143-1149

52. Agaba EA, Zaidi RM, Ramzy P, Aftab M, Rubach E, Gecelter G, Ravikumar TS, Denoto G (2009) Laparoscopic Hartmann's procedure: a viable option for treatment of acutely perforated diverticulitis. Surg Endosc 23:1483-1486

53. Faranda C, Barrat C, Catheline JM, Champault GG (2000) Twostage laparoscopic management of generalized peritonitis due to perforated sigmoid diverticula: eighteen cases. Surg Laparosc Endosc Percutan Tech 10:135-138

54. Taylor CJ, Layani L, Ghusn MA, White SI (2006) Perforated diverticulitis managed by laparoscopic lavage. ANZ J Surg 76(11):962-965

55. Karoui M, Champault A, Pautrat K, Valleur P, Cherqui D, Champault G (2009) Laparoscopic peritoneal lavage or primary anastomosis with defunctioning stoma for Hinchey 3 complicated diverticulitis: results of a comparative study. Dis Colon Rectum 52:609-615 
56. Favuzza J, Friel JC, Kelly JJ, Perugini R, Counihan TC (2009) Benefits of laparoscopic peritoneal lavage for complicated sigmoid diverticulitis. Int J Colorectal Dis 24:797-801

57. Sauerland S, Agresta F, Bergamaschi R, Borzellino G, Budzynski A, Champault G, Fingerhut A, Isla A, Johansson M, Lundorff P, Navez B, Saad S, Neugebauer EA (2006) Laparoscopy for abdominal emergencies: evidence-based guidelines of the European Association for Endoscopic Surgery. Surg Endosc 20:14-29

58. Santaniello M, Bergamaschi R (2006) Perforated diverticulitis: should the method of surgical access to the abdomen determine treatment? Colorectal Dis 9:494-495

59. Essani R, Bergamaschi R (2009) Laparoscopic peritoneal lavage for generalized peritonitis due to perforated diverticulitis. $\mathrm{Br} \mathrm{J}$ Surg 96:118

60. O'Sullivan GC, Murphy D, O'Brien MG, Ireland A (1996) Laparoscopic management of generalised peritonitis due to perforated colonic diverticula. Am J Surg 171:432-434
61. Polk HC Jr (1979) Generalized peritonitis: a continuing challenge. Surgery 86:777-778

62. Cheadle WG, David A, Spain DA (2003) The continuing challenge of intra-abdominal infection. Am J Surg 186:15-22

63. Lohrmann C, Ghanem N, Pache G, Makowiec F, Kotter E, Langer M (2005) CT in acute perforated sigmoid diverticulitis. Eur J Radiol 56:78-83

64. Stijn Blot S, De Waele JJ (2005) Critical issues in the clinical management of complicated intra-abdominal infections [review]. Drugs 65:1611-1620

65. Soumian S, Thomas S, Mohan PP, Khan N, Khan Z, Raju T (2008) Management of Hinchey II diverticulitis. World J Gastroenterol 14:7163-7169

66. Men S, Akhan O, Köroglu M (2002) Percutaneous drainage of abdominal abscess. Eur J Radiol 43:204-218 